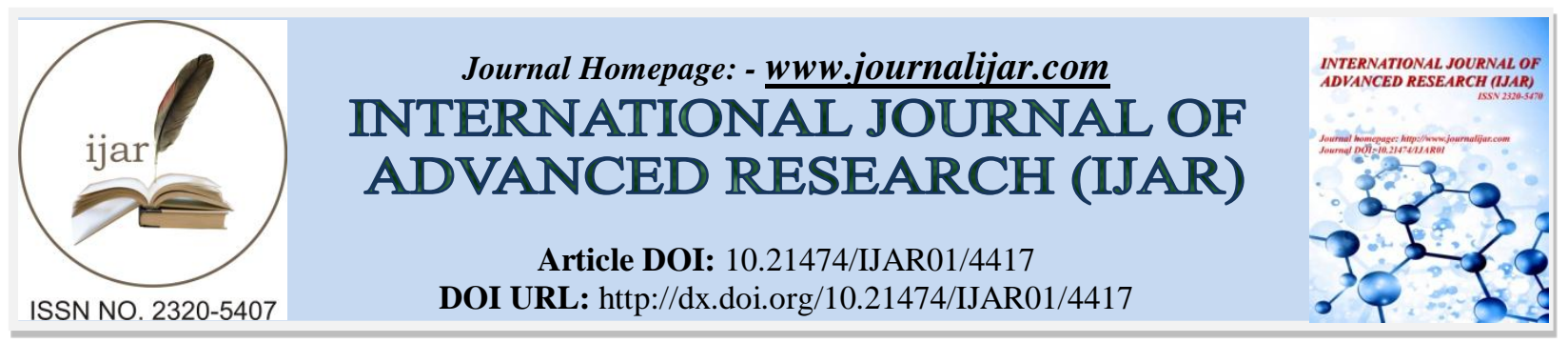

RESEARCH ARTICLE

\title{
KNOWLEDGE AND PRACTICES OF BEAUTY SHOP WORKERS REGARDING BLOOD-BORNE DISEASES IN ABHA AND KHAMIS MUSHAIT: A CROSS-SECTIONAL STUDY.
}

\author{
Leslom Abdullah, Alzilaee Anfal, Alahmari Sarah, Alamry Shatha, Jubran Wafaa, Almusra Hatim and \\ Leslom Salman. \\ College of Medicine, King Khalid University Abha, Kingdom of Saudi Arabia.
}

\section{Manuscript Info}

.

Manuscript History

Received: 08 April 2017

Final Accepted: 10 May 2017

Published: June 2017

Key words:-

Viral blood-borne diseases, Hepatitis B Virus, Hepatitis C Virus, Human Immunodeficiency

Virus, beauty shops, Saudi Arabia

\section{Abstract}

In Saudi Arabia, Human Immunodeficiency Virus (HIV) suggested low incidence but increasing, whereas Hepatitis B (HBV) is steadily declining but conflicting for Hepatitis $\mathrm{C}(\mathrm{HCV})$. Several reports showed that the negligent use of instruments in beauty shops poses risk towards the transmission of these blood-borne diseases. Hence, this study assessed the knowledge and practices of the beauty shop workers regarding HBV, HCV, and HIV in Abha and Khamis Mushait, Saudi Arabia. 242 respondents from 144 conveniently selected saloons and barber shops were selected as settings. Findings showed that majority are female (62.4\%), high school graduates (42.1\%), with 6-10 years working experience (50.8\%), monthly earns 1,000-3,000 SAR (57.9\%) and unaware of vaccination (90.1\%). High level of education ( $\mathrm{p}<0.0001)$, upper age $(\mathrm{p}<0.001)$ and female gender $(p<0.001)$ were significantly knowledgeable whereas high earners significantly have poor knowledge $(p<0.001)$. The practices of the beauty shop workers will likely predispose them to HBV, HCV and HIV as only $75 \%$ agreed of the risk when not gloving and sterilizing. The respondents showed insufficient knowledge and their current practices are at risk to spreading these infections. The link of gender, age, education and income suggest implications on strategically prioritizing screenings and trainings at the primary level specific for these professions on towards these viral blood-borne pathogens.

\section{Introduction:-}

Recent global reports showed 130-150 Hepatitis C-, 240 Hepatitis B-, and 38 HIV-confirmed cases, expressed in millions, in 2015 (World Health Organization or WHO, 2016 ${ }^{\mathrm{a}}$; WHO, 2016 ${ }^{\mathrm{b}}$ ). Hepatitis B (HBV), Hepatitis C $(\mathrm{HCV})$ and the Human Immunodeficiency Virus (HIV) are transmissible viruses with similar modes of transmission are among the top leading causes of infectious diseases worldwide. World report of estimates showed that over 30 million individuals has HIV, 350 million are infected with HBV, and 200 million have acquired HCV (United Nations, 2003). In Saudi Arabia, HIV suggested low incidence but increasing patterns were recorded (Ministry of Health, 2015). Furthermore, data in hepatitis evidently showed a steady decline in HBV but conflicting for HCV (Abdo and Sanai, 2015). 
HIV cases in Saudi Arabia was reported in 1984. The Ministry of Health launched the National AIDS Program to enhance awareness in the kingdom under the directorate of Public Health (Al-Mazrou et al., 2005). Some of the issues relevant to HIV in the kingdom are the increasing incidence, incomplete HIV surveys, underestimating the burden of the diseases, late presentation of AIDS, widespread stigmatization, and the scarcity of published data (AlGhanim et al., 2005, Al-Mazrou et al. 2005, Badahdah, 2005, Memish et al., 2015). The kingdom has implemented the international guidelines since no national guidelines has been initiated on the use of Antiretroviral Therapy or ART. Moreover, the number of patients receiving the treatment is reportedly lower than the projected compliance (Memish et al., 2015).

Hepatitis C virus data is still limited in the kingdom (Madani, 2007). HCV has been notifiable since 1990 and cases are reported to the Ministry of Health in Riyadh. Based on records, an estimate of 1,247 HVC infections may occur per region and that accounts to $0.124 \%$. Adults are mostly affected than children and where mostly linked to sharing of needles like substance abuse which is an increasing problem in the kingdom (United Nations, 2003). In the absence of HCV vaccine, the government is ensuring safe blood and organ transfer, safe use of sharp objects, and implementation of proper infection control healthcare settings.

Moreover, Hepatitis B virus is the leading cause of chronic liver disease specifically cirrhosis and hepatocellular carcinoma (Alhuraiji et al., 2014). The virus is considered endemic in Asia and Africa which were shown to have majority of the cases (Hoffmann and Thio, 2007). In 2007, Saudi Arabia has HBV prevalence among adults of $0.22 \%$ with average reported prevalence of $0.15 \%$ with wide variations occurring between regions (Madani, 2007).

Co-infections between these three viral blood-borne diseases has been reported in several studies. According to Alhuraiji et al. (2014), HBV and HCV are among the leading causes of death in HIV-infected patients. They represent significant public health concerns in the HIV population The prevalence of HBV and HCV in HIV infections are 10-20 times higher than the general population (Sulkowski, 2003).

These blood-borne viral diseases are considered costly and the non-sexual transmission has been found to occur in beauty therapy and hairdressing business establishments (Mele et al., 1995). The viral spread has been linked to the poor knowledge and negligent use of instruments which could potentially serve as vehicle for viral transmission (Demir et al., 2014). The use of unsterilized skin penetrating instruments like scissors, razors and blades is the primary mode of transfer of pathogens from the infected to the uninfected individuals (Biadgelen, et al. 2012). Shavers causes micro-trauma causing contamination. The lipid structure of the outer surface of the blood-borne viruses keep them protected on unsterilized instruments (Khandiat et al., 1999). The contaminated and reused instruments when not properly disinfected poses a relative risk for transmission (Janjua, and Nizamy, 2004). Several reports documenting the lack of knowledge infectious diseases among barbers, haircutters and hairdressers has been explored to aggravate the epidemic rise of blood-borne diseases.

In Saudi Arabia, there were limited data which shows that infection control procedures are practiced and monitored among beauty shops like saloons and barbershops. These business establishments are often visited by most people for aesthetic and hygiene purpose which poses risk to accidental cuts or skin penetrations. Hence, this present study aimed to evaluate the knowledge and practices on HBV, HCV and HIV among beauty shop workers in the two selected cities in Saudi Arabia. In this study, the assessment for HIV and Acquired Immunodeficiency Syndrome or AIDS are interchangeable since both belonged to the same disease transmission and infectious agent.

\section{Methods:-}

\section{Research Design:-}

This present study used cross-sectional descriptive research design. The design was used to describe the knowledge and practices of the respondents toward HIV, HBV and HCV transmission. The demographic profile was correlated to the respondent's knowledge and practices.

\section{Settings:-}

The study was conducted in 144 different saloons and barbershops in Abha and Khamis Mushalt, Saudi Arabia. These sub-regions are located in Aseer which is southwest of Saud Arabia. Khamis Mushait is situated east of Abha. The region has 30 primary health care centers and most of the patients used these centers for emergency services. Among the reported in Aseer, $568 \mathrm{HCV}$ cases and but lacks concrete data on HBV. According to Memish et al. 
(2015), the southern region accounts $23 \%$ whereas the western was $53 \%$ of the total cases of patients with HIV in the kingdom.

\section{Samples:-}

Convenient sampling was used in the selection of 242 beauty shop workers. This technique was preferred due to no known data from the regional offices on the total number of registered saloons and barber shops in Abha. In this study, the respondents' inclusion criteria include that he or she (1) must be working as either haircutters, hairdressers, manicurists and other relevant practices, (2) has been in this profession for more than 1 year, and (3) currently working in the selected beauty shops in Abha.

\section{Research Instrument:-}

A standardized questionnaire translated to Arabic version which was proven valid and reliable by by Ataie et al. (2013) was utilized in the data collection. The demographic data included gender, educational status, age, work duration, and average income which are in items 1 to 5 accordingly. Items 6 to 7 pertains to the practices of the respondents in their workplace. These items asked their use of risky tools, contamination, personal protective equipment and handwashing. Item 10-21 asked the respondents knowledge on HIV, HBV and HCV. The last three items, which include 22-24, asked whether patients are aware about them getting the infected by HIV, HBV and $\mathrm{HCV}$; with health certificate; and, getting vaccinated.

\section{Ethical Clearance:-}

Ethical clearance was secured from the Research Ethics Committee of the College of Medicine of King Khalid University with REC\# 2017-02-21. The informed consent was distributed among the respondents and orientation prior to data collection. The respondents were informed of their right to withdraw and that their participation is voluntary. The anonymity and confidentially of the respondents' information were kept all through-out the study and that the dissemination of findings is mainly for research purposes.

\section{Data Collection:-}

Data gathering was carried out for 2 months from February to March 2017 after the approval from the Research Ethics Committee and the Regional Office was secured. The survey was initiated by the co-authors themselves. After respondents' orientation, self-administered questionnaire was administered to eligible participants.

\section{Data Analysis:-}

Descriptive and inferential statistics were performed using SPSS Ver. 23.0. Data describing the knowledge and practices of the beauty shop workers are presented as weighted mean. To establish significant results, coefficient correlation and t-test results were utilized to assess relationship and differences among gender, age, educational status, work duration, and income to status in knowledge and practices towards HIV, HBV and HCV.

\section{Results:-}

\section{Demographic Characteristics:-}

As shown in Table 1, the majority of the respondents were female (62.4\%), high school graduates (42.1\%), with 610 years working experience (50.8\%), monthly earns 1,000- 3,000 SAR (57.9\%) and unaware of vaccination $(90.1 \%)$.

Table 1:- Demographic characteristics of the respondents $(\mathrm{N}=242)$.

\begin{tabular}{|l|l|}
\hline Profile & Frequency and Percentage \\
\hline Gender & $91(37.6 \%)$ \\
Fale & $151(62.4 \%)$ \\
\hline Age & \\
$21-30$ years & $49(20.2 \%)$ \\
$30-41$ years & $126(52.0 \%)$ \\
$41-50$ years & $53(22.0 \%)$ \\
Above 50 years & $14(5.8 \%)$ \\
\hline Educational status & $20(8.3 \%)$ \\
Elementary school graduate & \\
\hline
\end{tabular}




\begin{tabular}{|l|l|}
\hline Secondary school graduate & $46(19.0 \%)$ \\
High school graduate & $102(41.1 \%)$ \\
University graduate & $7430.6 \%)$ \\
\hline Work duration & \\
1- 5 years & $62(25.6 \%)$ \\
6- 10 years & $62(25.6 \%)$ \\
Above 10 years & $118(48.8 \%)$ \\
\hline Income & \\
Less than 1000 SAR & $10(4.1 \%)$ \\
1000-3000 SAR & $140(57.9 \%)$ \\
More than 3000 SAR & $92(38.0 \%)$ \\
\hline
\end{tabular}

Assessment of the knowledge on risky Tools:-

As shown in Table 2, the respondents' current knowledge on the use of tools in saloons and barber shops is moderate. When assessed on the use of tools for hairdressing and other relevant services such as razors, manicure sets, scissors, combs and brushes and hairclips, $<70 \%$ of the respondents perceived the practices as risky. The razors were ranked as the riskiest (67.8\%) compared to combs and brushes as the least (9.1\%). The findings implied that the respondents have limited information on the risk of the usual tools they used with their clients.

Table 2:- Assessment of the respondent's knowledge on risky tools.

\begin{tabular}{|c|c|c|}
\hline Items & Frequency & Percentage \\
\hline & & $67.8 \%$ \\
\hline Razor blades were risky & 164 & $25.6 \%$ \\
\hline Manicure pedicure sets were risky & 62 & $24.8 \%$ \\
\hline Scissors were risky & 60 & $9.1 \%$ \\
\hline Combs and brushes were risky & 22 & $15.7 \%$ \\
\hline Hairclips were risky & 38 & \\
\hline
\end{tabular}

\section{Assessment on the practices on avoiding Contamination:-}

In Table 3, findings showed that respondents were better in knowledge than in practice. They scored low in preventing contaminants on beauty shop working tools, wherein $<55 \%$ agreed on the application of sterilization techniques such as ultraviolet light, boiling, dry heat and autoclaving. The application of personal protectors was not mainly practiced especially using gloves $(63.6 \%)$. Most of the respondents wash hands every after customer (96.3\%). Other safety practices in the workplace of hairdressers were not mostly perceived by the respondents as essential as observed in their low agreements scores especially in handwashing technique when hands get dirty (1.7\%), and depilation (5.0\%).

Table 3:- Application of the respondents to avoid contamination in workplace.

\begin{tabular}{|c|c|c|}
\hline Items & Frequency & Percentage \\
\hline & & \\
\hline Sterilization technique & & $17.4 \%$ \\
\hline Ultraviolet & 42 & $14.9 \%$ \\
\hline Boiling method & 36 & $29.8 \%$ \\
\hline Dry heat & 72 & $39.7 \%$ \\
\hline Autoclave & 96 & $63.6 \%$ \\
\hline Personal protectors & 154 & $8.3 \%$ \\
\hline Never used gloves & 20 & $5.0 \%$ \\
\hline Wore gloves during waxing & 12 & $34.7 \%$ \\
\hline Wore gloves during depilation & 84 & \\
\hline Wore gloves every procedure & & $96.3 \%$ \\
\hline Frequency of handwashing & 233 & $1.7 \%$ \\
\hline After every customer & 4 & $3.3 \%$ \\
\hline When their hands got dirty & 8 & \\
\hline At the end of their working hours & & \\
\hline
\end{tabular}




\section{Relationship of the demographic profile toward knowledge and practices:-}

As depicted in the table 3, at 0.05 level of significance there is a significant difference in the knowledge in HIV, HBV and HCV between male and female hairdressers. Moreover, the female hairdressers were significantly knowledgeable in HIV, HBV and HCV than male hairdressers.

Table 4:- Relationship between gender and the level of knowledge in HBV, HCV and HIV.

\begin{tabular}{|l|l|l|l|l|}
\hline Variables & Frequency & Mean \pm SD & T value & $\mathrm{P}$ value \\
\cline { 1 - 3 } Male & 91 & $4.68 \pm 1.44$ & -11.273 & $\mathrm{P}<0.0001 *$ \\
\hline Female & 151 & $6.98 \pm 1.59$ & & \\
\hline
\end{tabular}

Note: *significant at 0.05

Table 5:- Relationship between educational status, age, work duration and income to the level of knowledge in HBV, HCV and HIV.

\begin{tabular}{|c|c|c|}
\hline Variables & Spearman Rank Correlation Coefficient & P value \\
\hline Educational Status & 0.364 & $\mathrm{P}<0.0001^{*}$ \\
\hline Age & 0.257 & $\mathrm{P}<0.0001^{*}$ \\
\hline Work Duration & 0.125 & 0.052 \\
\hline Income & -0.128 & $0.047^{*}$ \\
\hline Note: significant at 0.05 & & \\
\hline
\end{tabular}

As depicted in the table 5, there is a significant positive relationship between educational status and the knowledge in HIV, HBV and HCV with correlation value of 0.364 ( $\mathrm{p}<0.0001)$. This implies that hairdressers with higher educational status are more knowledgeable in AIDS, Hepa B and C than lower educational status.

The same is true with age, there is a significant positive relationship between age and knowledge in HIV, HBV and HCV with correlation value of 0.257 ( $\mathrm{P}<0.0001)$. Hence, the older hairdressers are more knowledgeable in HIV, $\mathrm{HBV}$ and $\mathrm{HCV}$ than younger hairdressers.

While for income, the relationship is negative with the knowledge in HIV, HBV and HCV with correlation value of -0.128 ( $\mathrm{P}=0.047)$. This suggests that hairdressers with lower income are more knowledgeable in HIV, HBV and $\mathrm{HCV}$ than hairdressers with higher income.

\section{Discussion:-}

In this study, the respondents showed limited information on the risk of the tools they used with their clients. The risk for blood-borne viral diseases in beauty salons among hairdressers and barbers were well established in several studies (Mele et al., 1995). In this workplaces, the chances that the penetrating instruments like scissors, razors and blades can transfer the viruses is highly feasible (Biadgelen, et al. 2012). The risk increases when the workers do not anticipate nor have the knowledge of the consequences of bringing cuts, abrasions and other skin penetrations using these risky tools on their clients.

The risk is higher among the respondents of this study when practice is compared to knowledge. Within almost half of the respondents do not follow the basic practices that can prevent contamination of the tools in their workplace. These include nearly half which do not perform sterilization techniques nor wear personal protectors like gloves. Handwashing which has been recognized as the basic and most cost-efficient way of preventing diseases was not also followed accordingly to the standards of preventing infections. In the study of Demir et al. (2013), below half of the hairdressers wash hands after each customer, when hands get dirty, and at the end of working hours. According to Johnson et al. (2001), barbers usually ignore the risk associated with blood-borne infections due to insufficient knowledge. The lack of knowledge has been linked to inappropriate practices. This can be exemplified by the study in Ankara among staff working manicure-pedicure and depilation which showed insufficient knowledge whereby their working tools were inadequately sanitized and sterilized (Johnson et al., 2001). When knowledge is not high, the application or practices may not only be suitable but also inefficient. The study of Hidiroglu et al. (2006) showed that their respondents performing manicure and pedicure used sanitization which is not scientific and effective. In this study, although respondents showed moderate knowledge, still in they have been inconsistent in the application of preventing decontamination which poses risks to their clients. 
According to Demir et al. (2013), awareness and knowledge on AIDS, HBV and HCV are essential for protection especially with the hairdressers and barbers. The use of gloves can serve as barriers to blood and bloody fluids which can serve as potential sources of HIV, HBV and HCV (Boztas et al., 2006). In this study, the respondents showed moderate knowledge. Contrasting results on knowledge were presented in the study by Hidiroglu et al. (2006) showing high awareness whereas in the study by Janjua and Nizamy (2004) in Pakistan showed low awareness among hairdressers in Pakistan on HBV. This result is typical in other relevant studies since knowledge and awareness can be influenced by personal and environmental factors. In this study, the moderate knowledge can be based according to the findings of Memish et al. (2015) that low awareness level in the western Saudi Arabia possibly explains the high prevalence on HIV and other infectious diseases in the region.

Another interesting finding in the study is that women are more aware and practice sterilization techniques favorably than men. The culture in Saudi Arabia remains mainly patriarchal and the role of women has been restricted to traditional beliefs and religion. It is in women that transfer of knowledge and the caring attitude is more profound than men. Thus, transfer of knowledge and sharing of learned practices are more likely to develop in Saudi female workers in saloons and beauty shops. The young workers were less knowledgeable than than the ones who have been working with the same job for years. Those with longer working experience has become competent and adaptive to the tasks and workplace over the years. Also, the study showed that high education is associated with better knowledge. This was supported by the study of Demir et al. (2013) and Bawany et al. (2014) which emphasized that educational level of hairdressers and barbers is very important. The more knowledgeable the workers the better they understand and consider blood-borne diseases when performing tasks. It is interesting to note that the high earners are the ones who are less knowledgeable and follows poor practices on decontamination. According to the study by Waheed et al. (2010), barbers in high earning saloons and barber shops are investing more on improving the ambience of the workplace rather than the prevention of diseases thus explaining the inappropriate decontamination procedures among high earners.

The sampling method used limits the findings within the covered areas; thus findings cannot be generalized over Saudi Arabia. The study also utilized self-administered questionnaire, thus responses are solely based on the respondents' perceptions and not in their actual performance.

\section{Conclusion:-}

The hairdressers' showed insufficient knowledge and their current practices were favorable to the likelihood of spreading the disease. The link of gender, age, education and income suggest implications on the strategic prioritization when performing screening and trainings in health centers pertaining to viral blood-borne pathogens. It is further recommended that Hepatitis and HIV testing should be made available for free to individuals who has the same occupational risks. Also, the health sectors are recommended to develop regulations and guidelines on the proper disposal of contaminated tools and practice efficient preventive methods against HIV, HBV and HCV. The policy should be enforced in these shops including awareness enhancement, regular trainings and licensing. These guidelines are recommended be forwarded to the different sectors of the primary health care units to enhance the hairdressers' compliance and improve public health awareness.

\section{References:-}

1. Abdo A, Sanai F. (2015). Viral hepatitis in Saudi Arabia. Saudi Medical Journal. 36 (7), 785-786.

2. Al-Ghanim SA. (2005) Exploring public knowledge and attitudes towards HIV/AIDS in Saudi Arabia. A survey of primary health care users. Saudi Medical Journal. 26: 812-818.

3. Alhuraiji A, Alaraj A, Alghamdi S, AlrbiaanmA, Alrajhi A. (2014). Viral hepatitis B and C in HIV-infected patients in Saudi Arabia. Annals Saudi of Medicine. 34(3), 207-210.

4. Al-Mazrou YY, Abouzeid MS, Al-Jeffri MH. (2005) Knowledge and attitudes of paramedical students in Saudi Arabia toward HIV/AIDS. Saudi Medical Journal. 26, 1183-1189. 5.

5. Ataei B, Shirani K, Alavian SM, Ataei M. (2013). Evaluation of knowledge and practice of hairdressers in women's beauty salons in Isfahan about Hepatitis B, Hepatitis C, and AIDS in 2010 and 2011. Hepatitis Monthly. 13 (3), e6125.

6. Badahdah A. (2005). Saudi attitudes towards people living with HIV/AIDS. International Journal of STD AIDS. 16: 837-848. 
7. Bawany FI, Khan MS, Shoaib AB, Naeem M., Kazi AN, Shehzad AM. (2014). Knowledge and practices of barbers regarding HIV transmission in Karachi: a cross sectional study. Journal of Community Health. 39, 951955.

8. Biadgelegn F, Belyhun Y, Anagaw B, Woldeyohannes D, Moges F, Bekele A. (2012). Potential risk of HIV transmission in barbering practice in Ethiopia: From public health and microbiological perspectives. BMC Public Health. 12(1), 707.

9. Boztaş G, Çilingiroglu N, Özvarış S B, Karaöz A, Karataş F, Kara G. (2006). Some opinions and practices about blood-borne diseases of people working in hairdresser and beauty salons in a neighborhood of Ankara. Journal of Nursing School. 60-68

10. Demir NA., Kolgelier K, Demir LS, Ozcimen S, Inkaya AC. (2014). The Knowledge and behavior of hairdressers and barbers on blood-borne diseases. Viral Hepatitis Journal. 20 (2), 67-71.

11. Hıdıroğlu S, Karavuş M, Topuzoğlu A, Şalva T. (2006). Information attitudes and behaviors of manicurepedicuring barbers about hepatitis B. 5 (4), 276-286.

12. Hoffmann CJ, Thio CL. (2007). Clinical implications of HIV and Hepatitis-B co-infection in Asia and Africa. Lancet Infectious Disease. 7, 402-409.

13. Janjua, NZ, Nizamy M A. (2004). Knowledge and practices of barbers about hepatitis B and C transmission in Rawalpindi and Islamabad. Journal of Pakistan Medical Association. 54(3), 116-119.

14. Johnson IL, Dwyer JJM, Rusen DI, Shahin R, Yaffe B. (2001). Survey of infection control procedures at manicure and pedicure establishments in North York. Canadian Journal of Public Health. 92(2), 134-137.

15. Khandiat DW, Ambadekar NN, Vasudeo ND. (1999). Knowledge and Practice about HIV transmission among barbers of Nagpur city. Indian Journal of Medical Sciences. 53, 167-171.

16. Madani TA. (2007). Hepatitis C virus infections reported in Saudi Arabia over 11 years of surveillance. Annals of Saudi Medicine. 27 (3), 191-194.

17. Mele A, Corona R, Tosti ME. et al. (1995). Beauty treatments and risk of parenterally transmitted hepatitis: results from the hepatitis surveillance system in Italy. Scandinavia Journal of Infectious Diseases. 27 (5), 441 444.

18. Memish A, Al-Tawfiq J, Filemban S, Qutb S, Fodail A, Bato A, Darweeish M. (2015). Antiretroviral therapy, CD4, viral load, and disease stage in HIV patients in Saudi Arabia: a 2001-2013 cross-sectional study. The Journal of Infection in Developing Countries. 9(7), 765-769.

19. Ministry of Health. MOH: ' 1,191 New AIDS Cases in the Kingdom during 2015'. Accessed at http://www.moh.gov.sa/en/Ministry/MediaCenter/News/Pages/News-2016-11-30-001.aspx on March 2017.

20. United Nations (2003). Global Illicit Drug Trends 2003. Office on Drugs and Crime. United Nations Publication Sales No. E03.V1.5,ISBN 92-1-148156-2, ISSN.

21. Sulkowski MS, Thomas DL. (2003). Hepatitis C in the HIV-infected person. Annals of Internal Medicine. 138, 197-207.

22. United Nations Program on HIV/AIDS. (2014). FastTrack: ending the AIDS epidemic by 2030. UNAIDS Information and Production Unit. Geneva, Switzerland.

23. Waheed, Y, Saeed U, Safi SZ, Chaudhry WN, Qadri I. (2010). Awareness and risk factors associated with barbers in transmission of hepatitis B and C from Pakistani population: Barber's role in viral transmission. Asian Biomedicine. 4(3), 435-442

24. World Health Organization. (2016 ${ }^{\mathrm{a}}$. Hepatitis A Factsheet, Accessed at http://www.who.int/mediacentre/factsheets/fs164/en/ on March 2017.

25. World Health Organization. $\left(2016^{\mathrm{b}}\right)$. Hepatitis B Factsheet. Accessed at: http://www.who.int/mediacentre/factsheets/fs204/en/ on March 2017.

26. World Health Organization. (n.d.). HIV. Accessed http://www.who.int/hiv/en/ on March 2017.

27. World Health Organization. $\left(2016^{\mathrm{c}}\right)$. Combating hepatitis B and C to reach elimination by 2030. WHO Publications. Geneva, Switzerland. 